\title{
EPR and FTIR Spectroscopies Study of Human Blood after Irradiation
}

\author{
M. Polakovs, ${ }^{1}$ N. Mironova-Ulmane, ${ }^{1}$ A. Pavlenko, ${ }^{1}$ E. Reinholds,${ }^{2}$ \\ M. Gavare, ${ }^{3}$ and M. Grube ${ }^{3}$ \\ ${ }^{1}$ Institute of Solid State Physics, University of Latvia, LV1063 Riga, Latvia \\ ${ }^{2}$ Nuclear Medicine Department, P. Stradins Clinical University Hospital, LV1002 Riga, Latvia \\ ${ }^{3}$ Institute of Microbiology and Biotechnology, University of Latvia, LV1010 Riga, Latvia
}

Correspondence should be addressed to M. Polakovs, mpolakovs@gmail.com

Copyright (C) 2012 M. Polakovs et al. This is an open access article distributed under the Creative Commons Attribution License, which permits unrestricted use, distribution, and reproduction in any medium, provided the original work is properly cited.

\begin{abstract}
In the present work we report results of investigations of human blood before and after radioisotope Tc ${ }^{99 \mathrm{~m}}$ diagnosis by electron paramagnetic resonance (EPR) and Fourier transform infrared (FTIR) spectroscopies. It is shown that EPR can detect the concentration of methaemoglobin and transferrin ions more accurately than any other technique. FTIR spectra indicated that radiation caused conformational and concentration changes of proteins. Hierarchical cluster analysis (HCA) was created as time-saving tool for discrimination of initial and irradiated in vivo human blood samples.
\end{abstract}

Keywords: EPR (electron paramagnetic resonance), hemoglobin, FTIR (Fourier transform infrared), spectroscopy, blood, radioisotope $\mathrm{Tc}^{99 \mathrm{~m}}$ diagnosis

\section{Introduction}

The study of blood and hemoglobin damage radiation is very important in order to understand the biological effects of ionizing radiation [1-6]. Various physical techniques are used to determine structural damage of hemoglobin after irradiation: absorption spectroscopy, IR spectroscopy [2], and Mossbauer and EPR spectroscopy $[6,8,9]$.

This work is one of our several investigations of the influence of ionizing radiation on human blood $[2,4,5,9]$.

EPR is the only technique that provides direct detection of free radicals and unpaired electrons in the sample. Common examples are transition metal ions, $\mathrm{Fe}^{3+}, \mathrm{Cu}^{2+}, \mathrm{Mn}^{2+}$, and $\mathrm{Co}^{2+}$, free radicals, typically carbon-, nitrogen-, or oxygen-containing compounds [6]. Many blood proteins use metal centres to bind and react with small molecules. For example, hemoglobin contains iron and gives red blood cells their colour. The iron group in hemoglobin transports oxygen around the body. When hemoglobin binds oxygen, ion $\mathrm{Fe}^{2+}$ does not change the charge but changes only its electronic configuration from high-spin configuration to low-spin configuration. 
FTIR spectroscopy has been successfully used to determine structural changes in erythrocytes in blood samples [3] and the molecular level changes in RBC proteins due to laser irradiation [1]. Reference [5] have used FTIR spectroscopy to study changes of blood when exposed to therapeutic doses of radiation from a He-Ne laser and identified changes in the Amide A, Amide I, Amide II, and Amide III absorption regions and also in the absorption bands of methyl, methylene, and phosphate groups. Our previous studies showed that resonance Raman scattering and FTIR spectroscopy indicate the irradiation effects on blood hemoglobin [4].

The aim of this study was to investigate the influence of irradiation on human blood by EPR and FTIR spectroscopy.

\section{Materials and Methods}

In present work we study the blood of patients before and after radioisotope $\mathrm{Tc}^{99 \mathrm{~m}}$ diagnosis by electron paramagnetic resonance and Fourier transform infrared spectroscopies.

The samples of blood were received from the Nuclear Medicine Department, P. Stradins Clinical University Hospital of Latvia, from patients under medical treatment. Venous blood was donated by consenting patients before and after radioisotope $\mathrm{Tc}^{99 \mathrm{~m}}$ diagnosis and collected under air in glass tubes containing a small amount of heparin used as an anticoagulant. Radioactive pharmaceutical $\mathrm{Tc}^{99 \mathrm{~m}}$ was injected into the patients, and venous blood samples were taken before injection and in two hours after diagnosis. Blood without any anticoagulant was also tested and showed no difference with respect to sodium citrate-treated or heparin blood. Samples for EPR measurements were immediately frozen in liquid nitrogen.

The EPR spectra of frozen blood were measured on a BRUKER EMX-6/1 spectrometer equipped with an Aspect 2000 data system. An ER 4102 ST Universal X-Band Resonator (TE102 mode) was used. The $g$-factors of EPR signals were determined by reference to the external magnetic field value measured by a Bruker ER 035 Gaussmeter and the microwave frequency measured by a Systron Donner 6235A frequency counter. The EPR signal intensities in blood were measured against fixed standard signals using the standard crystal $\mathrm{MgO}\left(\mathrm{Cr}^{3+}\right)$ placed in resonant cavity. The spectra were recorded at microwave power $6.2 \mathrm{~mW}$, applying magnetic field modulation of $100 \mathrm{kHz}$ and amplitude $1 \mathrm{mT}$. One spectrum is obtained averaging 20 scans with receiver time constant at $25 \mathrm{~ms}$.

FTIR analysis was performed using $1-6 \mu \mathrm{L}$ of initial (control/pre-radiation) and blood after radionuclide diagnosis water suspension poured out by drops on a 384 place silicon plate and dried at $T<50^{\circ} \mathrm{C}$. Absorption spectra were recorded on an HTS-XT microplate reader (Bruker, Germany) over the range $4000-400 \mathrm{~cm}^{-1}$, with a resolution of $4 \mathrm{~cm}^{-1}$. Spectra recorded in absorption range $0.25-$ 0.80 (the intensity of absorption band is proportional to the concentration) were used for quantitative analysis [9]. Data were processed by OPUS 6.5 using spectra 2nd derivatives, integration and HCA.

\section{Results}

We report results of investigations of blood of patients before and after radioisotope $\mathrm{Tc}^{99 \mathrm{~m}}$ diagnosis by EPR and FTIR spectroscopies. 


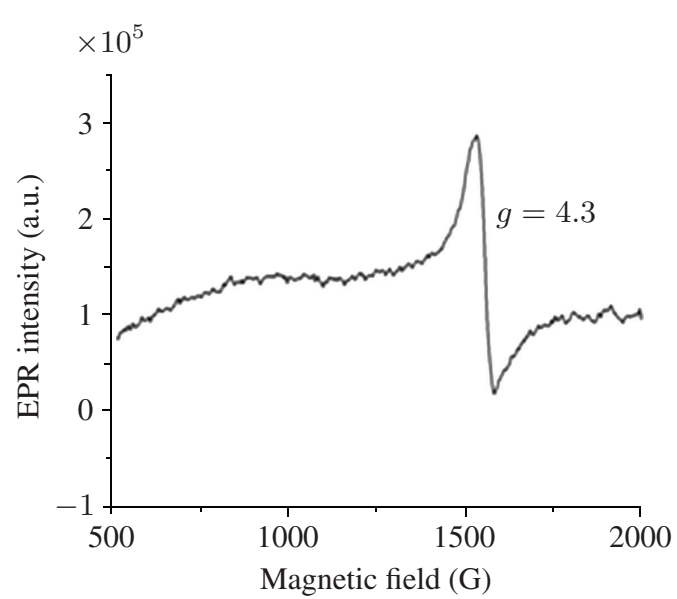

(a)

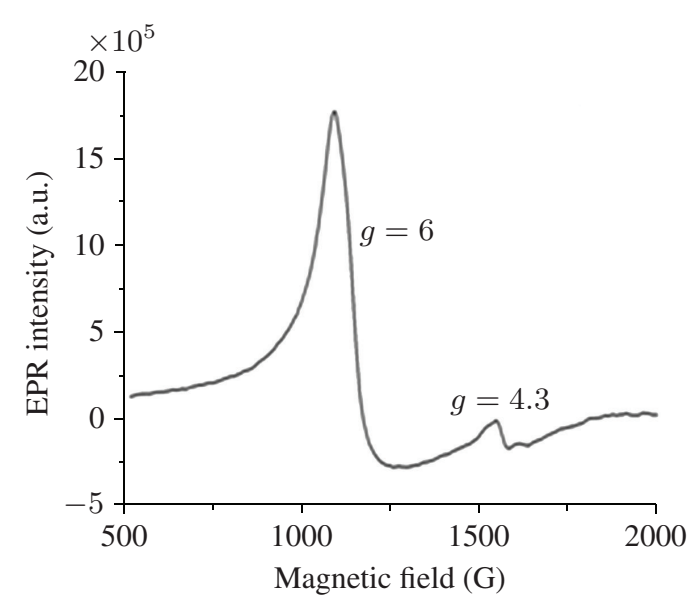

(b)

Figure 1: EPR spectra of blood before (a) and after (b) radioisotope $\mathrm{Tc}^{99 \mathrm{~m}}$ diagnosis.

The important parameter of EPR spectra is $g$-factor. The $g$-factor of an EPR sample determines the position in the magnetic field (at a given microwave frequency) where an EPR transition will occur:

$$
g=\frac{h \nu}{\beta B_{0}}
$$

where $h$ is Planck's constant, $\nu$ is microwave frequency, $\beta$ is Bohr magneton, and $B_{0}$ is magnetic field.

The EPR spectra of patients' blood before radioisotopes diagnosis consist EPR signal with $g$ factor 4.3 due to transferrin Figure 1(a). The EPR spectra of patients' blood after radioisotopes diagnosis consist of EPR signals with $g$-factor 4.3 due to transferrin and $g$-factor 6.0 due to methemoglobin in high spin state (Figure 1(b)).

Methemoglobin (ferric form of hemoglobin) is the form of hemoglobin when iron $\mathrm{Fe}^{2+}$ in the heme is oxidized to the $\mathrm{Fe}^{3+}$ ferric state $[\mathrm{Ar}] 3 \mathrm{~d} 5$ due to influence of ionizing radiation. This form of hemoglobin is not able to bind oxygen. This compound is unable to deliver oxygen to tissues; therefore, it is advantageous to convert this $\mathrm{Fe}^{3+}$ form of hemoglobin into the $\mathrm{Fe}^{2+}$ ferrous state so that tissues can get the oxygen that they need.

IR spectra profiles (Figure 2) showed variations in the overall composition of blood samples from different patients, like high total carbohydrate (mainly glucose) or lipid concentrations that are known to be characteristic or variable for particular patients. Evaluation of spectra profiles showed that in irradiated blood samples the concentration of proteins was lower while the concentration of lipids increased. This was in agreement with the results of quantitative analysis. For example, the protein concentration in the initial sample was of $59 \%$ dry weight (DW) and $52 \%$ DW after irradiation and lipid concentration of $1 \% \mathrm{DW}$ and $2.3 \% \mathrm{DW}$, correspondingly. On the basis of our previous studies [5] as discriminative for irradiation effects were chosen Amid I and II bands of proteins.

The ratio of Amid I $\left(1657 \mathrm{~cm}^{-1}, \beta\right.$-sheet conformation) and Amid II $\left(1544 \mathrm{~cm}^{-1} \alpha\right.$-sheet confirmation) band intensities was significantly higher in the initial samples. This indicates the change 


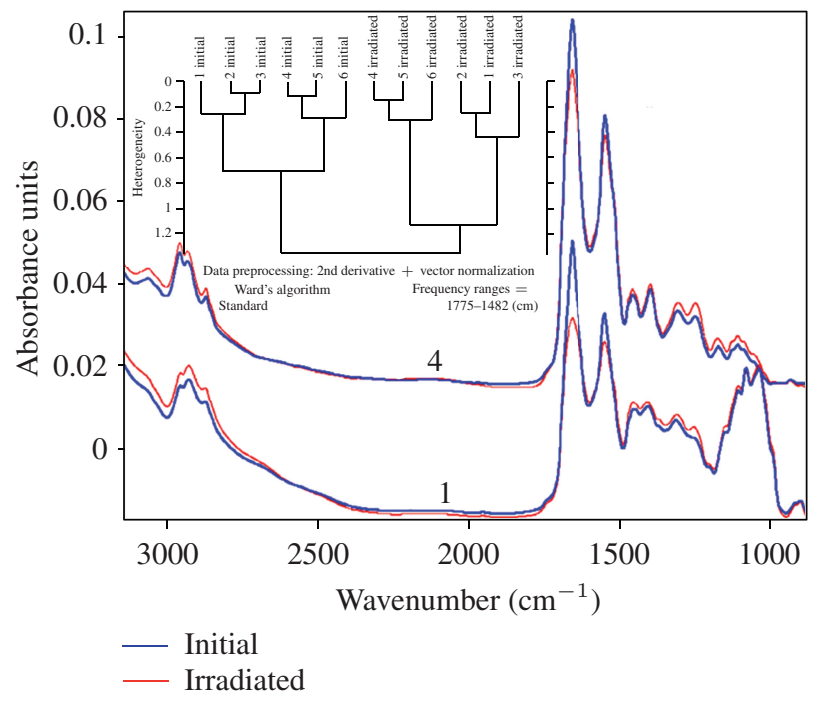

Figure 2: Normalized FTIR spectra and cluster analysis of initial and irradiated blood samples of six individuals. Blue line indicates initial samples, and red line indicates irradiated samples. For cluster analysis vector normalization, second derivative $1775-1482 \mathrm{~cm}^{-1}$.

of protein configuration - dominant of $\alpha$ or $\beta$ sheet confirmations, as the Amide I peak centered shifts down indicate the change in the overall protein conformational state within the cell [2]. Further HCAs using various discriminative regions were created. The dendrogram of HCA using vector normalization, 2nd derivative spectra in region $1775-1482 \mathrm{~cm}^{-1}$, and Ward's algorithm is shown in Figure 2. It can be seen that HCA clearly discriminated initial and irradiated samples confirming the radiation-caused changes in the blood.

\section{Conclusions}

Evaluation of FTIR spectra indicated the influence of ionizing radiation on the blood biochemical composition. HCA was shown to be useful for quick discrimination of initial and irradiated blood samples. Thus, FT spectroscopy was shown to be a quick and informative method with several advantages in comparison with conventional biochemical methods. Taking into account that FTIR spectroscopy is a quick and highly informative method that needs small amounts of sample (in our case even few microliters) and when using microplate reader even no sample pretreatment is necessary, it is very promising for studies of irradiation effects on blood cells.

Evaluations of EPR spectra data show that methemoglobin level in the blood of patients after radioisotope $\mathrm{Tc}^{99 \mathrm{~m}}$ diagnosis is higher than before diagnosis. We assume that ion $\mathrm{Fe}^{2+}$ heme hemoglobin is oxidized to the $\mathrm{Fe}^{3+}$ heme by radiation. The heightened level of methemoglobin is a subject for investigation since it has a significant role in vital functions of the human organisms. EPR can detect the concentration of methemoglobin ions more accurately than any other technique. 


\section{Acknowledgments}

This work was supported by the Latvian Government grants (no. 09.1213), The Latvian State Research Program "Development of innovative multifunctional materials, signal processing and information technology for competitive science-intensive products" project no. 4 "New materials and technologies for evaluating biological tissue, and replace."

\section{References}

[1] V. Ghadage and G. K. Kulkarni, "Effects of Nd:YAG laser irradiation on human erythrocytes in vitro," International Journal of Integrative Biology, vol. 9, pp. 149-151, 2010.

[2] M. Polakovs, N. Mironova-Ulmane, N. Kurjane, E. Reinholds, and M. Grube, "Micro-Raman scattering and infrared spectra of hemoglobin," in Proceedings of the 6th International Conference on Advanced Optical Materials and Devices (AOMD-6), pp. 1-8, August 2008.

[3] H. Y. N. Holman, R. Goth-Goldstein, E. A. Blakely, K. Bjornstad, M. C. Martin, and W. R. McKinney, "Individual human cell responses to low doses of chemicals studied by synchrotron infrared spectromicroscopy," in Proceedings of the Biomedical Spectroscopy: Vibrational Spectroscopy and other Novel Techniques, A. Mahadevan-Janen and G. J. Puppels, Eds., pp. 57-63, January 2000.

[4] N. Mironova-Ulmane, M. Polakovs, A. Pavlenko et al., "Estimation of internal and external exposition in retrospective dosimetry of Chernobyl clean-up workers," in Proceedings of the 5th International Conference on Medical Physics, pp. 55-59, Kaunas University of Technology, Kaunas, Lithuania, 2007.

[5] N. Mironova-Ulmane, M. Polakovs, A. Pavlenko et al., "The optical and EPR spectra of $\mathrm{Fe}^{2+}$ and $\mathrm{Fe}^{3+}$ ions in the blood of the Chernobyl clean-up workers," in Proceeding of World Congress on Medical Physics and Biomedical Engineering 2006, Springer, 2007.

[6] C. Petibois and G. Déléris, "Evidence that erythrocytes are highly susceptible to exercise oxidative stress: FTIR spectrometric studies at the molecular level," Cell Biology International, vol. 29, no. 8, pp. 709-716, 2005.

[7] G. A. Zalesskaya and I. I. Kalosha, "Effect of in vivo irradiation of blood by low-intensity emission from a He-Ne laser on molecular components of blood," Journal of Applied Spectroscopy, vol. 76, no. 5, pp. 720-726, 2009.

[8] M. Grube, M. Bekers, D. Upite, and E. Kaminska, "IR-spectroscopic studies of Zymomonas mobilis and levan precipitate," Vibrational Spectroscopy, vol. 28, no. 2, pp. 277-285, 2002.

[9] M. Poïakovs, N. Mironova-Ulmane, A. Pavlenko, T. Zvagule, N. Kurjane, and N. Gabruševa, "The investigation of Chernobyl clean-up workers blood by EPR technique," in Proceedings of International Conference of Medical Physics in the Baltic States, pp. 137-141, Kaunas, Lithuania, October 2010. 


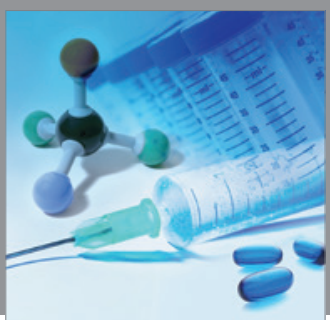

International Journal of

Medicinal Chemistry

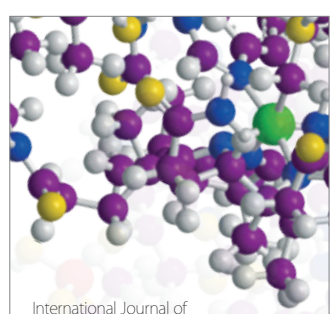

Carbohydrate Chemistry

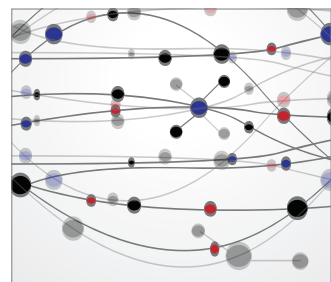

The Scientific World Journal
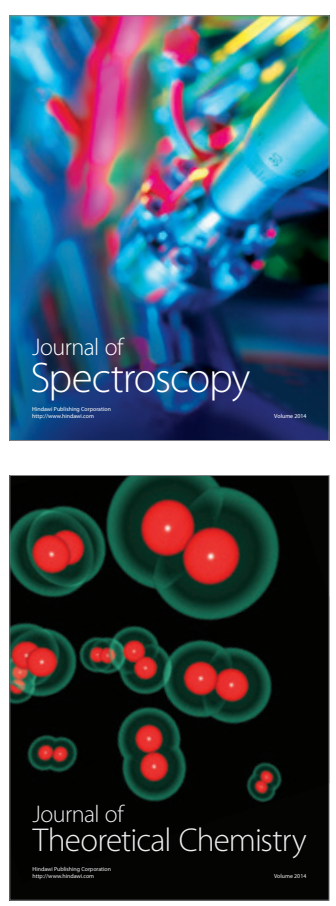
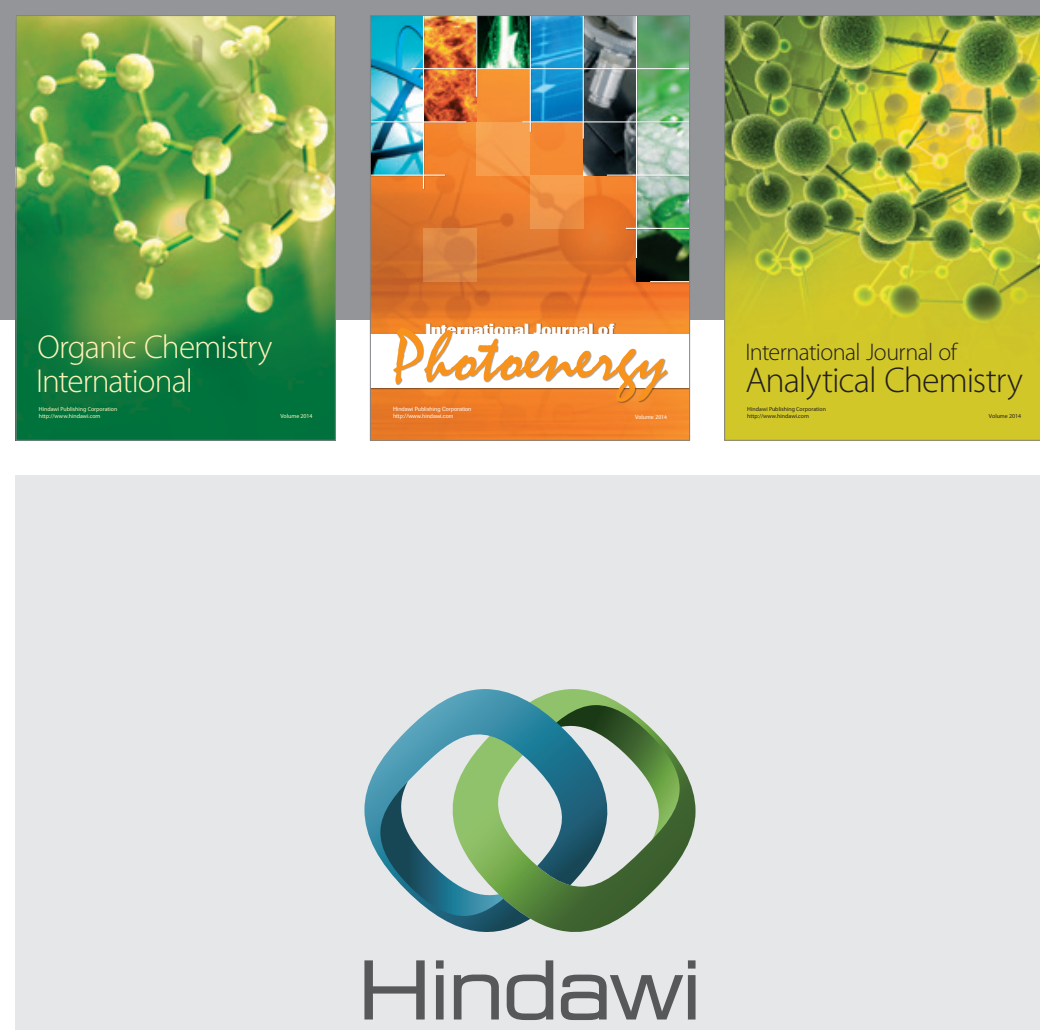

Submit your manuscripts at

http://www.hindawi.com
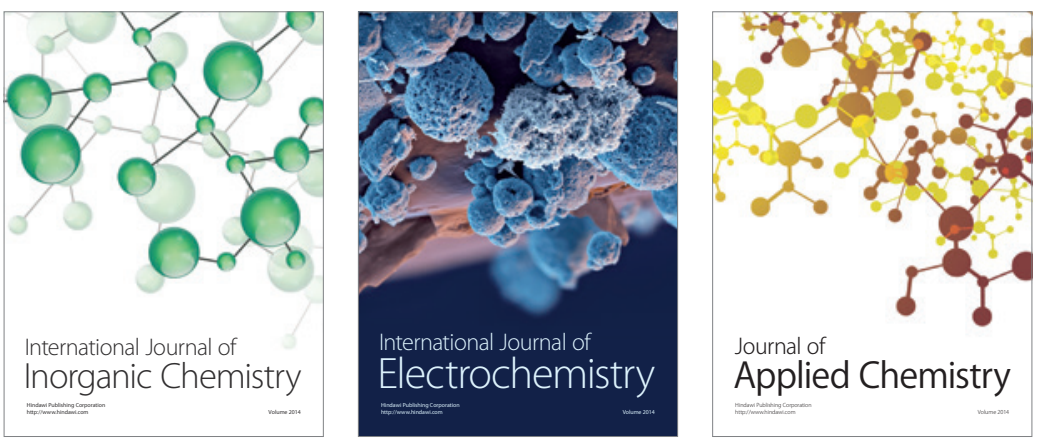

Journal of

Applied Chemistry
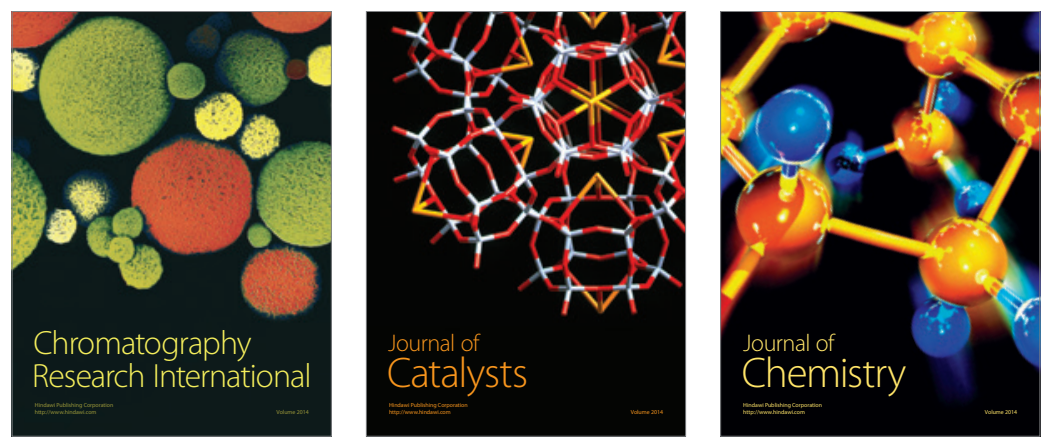
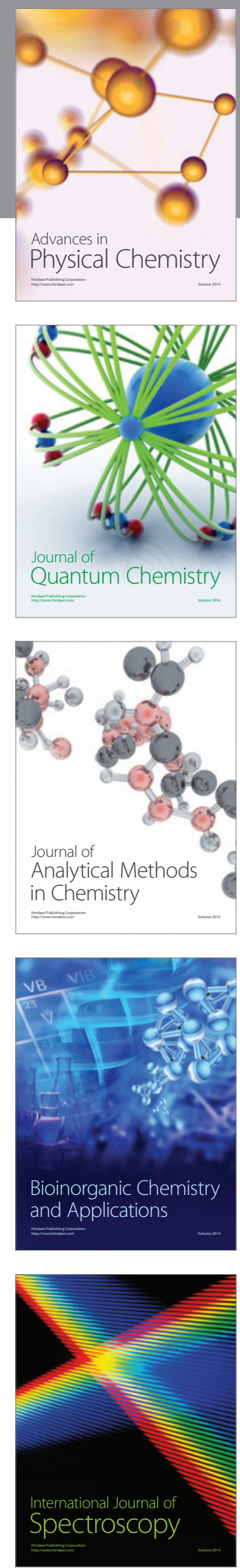